\title{
ALIGNING KNOWLEDGE STRATEGY AND COMPETITIVE STRATEGY IN SMALL FIRMS
}

\author{
Carlo BAGNOLI ${ }^{1}$, Claudio GIACHETTI ${ }^{2}$ \\ Department of Management, Ca' Foscari University of Venice, \\ 873 Cannaregio, S. Giobbe, 30121 Venice (VE), Italy \\ E-mails: ${ }^{1}$ bagnoli@unive.it; ${ }^{2}$ claudio.giachetti@unive.it (corresponding author)
}

Received 21 November 2011; accepted 26 June 2012

\begin{abstract}
Despite the claim of more and more scholars that there is a need to align knowledge strategies with competitive strategies, little research allows for more precise conceptualizations concerning this problem of inter-level strategic fit, and few have attempted an empirical investigation. This is especially true in the specific context of small firms (SFs), despite the fact, that their knowledge-based resources are more important than their property-based resources. This study aims to investigate, through a quali-quantitative analysis carried out on a sample of SFs in northeast Italy, the alignment between knowledge strategies and competitive strategies. We have identified two types of competitive strategies pursued by SFs, i.e. human resource-based (HR-based) and product and customer service quality-based (PCSQ-based). We have also identified two types of internal knowledge strategy, i.e. exploitation strategy of internal knowledge, and exploration strategy of internal knowledge, as well as two types of external knowledge strategy, i.e. exploitation strategy of external knowledge, and exploration strategy of external knowledge. Our findings reveal that SFs pursuing HR-based competitive strategies tend to adopt exploitation strategies of both internal and external knowledge, while firms pursuing PCSQ-based competitive strategies tend to adopt exploration strategies of both internal and external knowledge.
\end{abstract}

Keywords: knowledge management strategy, competitive strategy, small firms, internal knowledge, external knowledge, coherence, strategic fit.

JEL Classification: C12, C38, L21.

\section{Introduction}

According to the knowledge-based view of the firm, the primary function of an economic organization is the development and deployment of knowledge (Grant 1996; Nonaka 1994; Spender 1996). Sustainable competitive advantage and performance differences between firms are results of their different knowledge bases, and thus of their different capabilities in generating and applying knowledge. Knowledge management can be considered to be one of the most important dynamic capabilities, and the principal driver of all other competencies and capabilities (Kogut, Zander 1992). The first knowledge management studies focused on the properties of different types of knowledge, particu- 
larly on the distinction between tacit and explicit knowledge, and on the relationship between individual and social knowledge (Nonaka 1994; Spender 1996). Knowledge management was initially perceived as a problem concerned with the diffusion of information technology, useful for making individual knowledge explicit, and/or related with the important role that social interactions play in the sharing of tacit knowledge. Subsequently, knowledge management scholars have elaborated on the idea that the knowledge management and knowledge strategy must be driven properly by the firm's competitive strategy (e.g. Whitehill 1997; Drew 1999; Zack 1999).

The analysis of several management consulting firms by Hansen et al. (1999) identifies two distinct knowledge strategies: one emphasizing the reuse of knowledge, and thus the importance of information technology for making individual knowledge explicit; and the other the sharing of tacit knowledge, and therefore the importance of social interactions. These strategies do not, however, depend on the a priori emphasis given to technological factors over and above social factors, or vice versa, but rather reveal the existence of different competitive strategies. In fact, the authors find that the first knowledge strategy was implemented by those consulting firms that have standardized-mature products, and that exploit the explicit knowledge of their databases, while the second knowledge strategy was implemented by those consulting firms that have customized, innovative products, and which exploit the tacit knowledge of their employees.

However, Zack $(2002,2005)$ finds that, when analyzing firms that are not in the business of selling knowledge, the alignment between knowledge strategies and competitive strategies (i.e. how well these strategies complement and support each other relative to the firm's overall strategic objectives) appears much weaker. Moreover, he argues that knowledge strategy is not confined to the choice of how to exploit the existing (tacit and/or explicit) knowledge, but also includes the choice regarding how to create and acquire new knowledge. In particular, he argues that:

"a knowledge strategy ... can be described along two dimensions reflecting its degree of aggressiveness. The first addresses the degree to which an organization needs to increase its knowledge in a particular area $v s$. the opportunity it may have to leverage existing but underexploited knowledge resources, that is, the extent to which the firm is primarily a creator $v s$. user of knowledge. The second dimension addresses whether the primary sources of knowledge are internal or external" (Zack 2002: 134).

Nevertheless, despite the claim of more and more scholars that there is a need to align knowledge strategies with competitive strategies (Bagnoli, Roberts 2011), little research allows for more precise conceptualizations concerning this problem of inter-level strategic fit (Nath, Sudharshan 1994) and even less attempts an empirical investigation (Bagnoli, Vedovato 2012; Halawi et al. 2006). This is especially true in the specific context of small firms (SFs), despite the fact that their knowledge-based resources are more important than their property-based resources, and that they are the engine of economic growth (Wiklund, Shepherd 2003). Furthermore, this problem of inter-level strategic fit seems to vary among firms, according to their degree of alignment between those personnel responsible for the knowledge strategy and those personnel responsible 
for the competitive strategy (Zack 2002; Smith, McKeen 2003). In SFs the alignment is maximal since their tendency is to have only one key strategic decision-maker: the owner-manager.

This study aims to investigate, through a quali-quantitative analysis carried out on a sample of SFs in northeast Italy, the alignment between knowledge strategies and competitive strategies. The rest of the paper is structured as follows. First, we provide a review of the main knowledge strategies identified in the extant literature. Second, we focus on the main contributions analyzing the alignment between knowledge strategies and competitive strategies. Third, we highlight the main gaps in the previous alignment relationship, in the specific context of SFs. Fourth, we derive hypotheses on the analyzed relationship. Next, we describe the methodology and variables used in the analyses. Finally, we close the paper with a discussion of the results, and the main implications for scholars and practitioners.

\section{Knowledge strategies}

Knowledge strategy is the set of guidelines for the development and deployment of knowledge. Bierly and Daly argue that:

"In its basic form, a knowledge strategy can be viewed as a firm's set of strategic choices regarding two knowledge domains: (1) the creation or acquisition of new knowledge and (2) the ability to leverage existing knowledge to create new organizational products and processes" (Bierly, Daly 2002: 278-279).

According to the "radicalness of the learning process" (Bierly, Chakrabarti 1996), authors generally distinguish knowledge strategies into two macro typologies: exploration and exploitation.

A knowledge exploration strategy emphasizes the generation of radical new knowledge, challenging the existing frame of reference, and thus engaging in double-loop learning (Argyris, Schon 1978). It includes activities captured by terms such as search, variation, risk-taking, experimentation, discovery and innovation. To create radical new knowledge, organizations should invest in R\&D activities for developing (occasional or planned) designed experimentation (Bierly, Chakrabarti 1996), and encouraging on-thejob individual experimentation. Furthermore, they should create organizational members' job descriptions, and competence balance sheets, as well as paper and electronic databases to formalize and diffuse best practices. Finally, they should organize meetings, to share existing and new generated knowledge among organizational members, as well as develop internal training and teamwork: "By helping employees develop integrative skills, managers can harness the creative energy produced by this process to generate new ideas and solutions" (Bierly, Daly 2002: 286). A knowledge-exploration strategy entails higher costs and increased risk for a firm because it may disrupt the rules and routines within the organization, but is more likely to lead to a sustainable competitive advantage (March 1991; Spender 1992).

In contrast, a knowledge-exploitation strategy emphasizes the incremental enhancement of the existing knowledge, typically done within an existing frame of reference, thus 
leading to single-loop learning (Argyris, Schon 1978). This includes activities such as refinement, improvement, static efficiency, enhancement and amelioration. To enhance the existing knowledge incrementally, organizations should encourage learning "by doing" and "by using", and thus by on-the-job individual experimentation. Codification processes, to formalize and diffuse best practices, are less critical since: "experienced employees will be the primary source of improvements based on tacit knowledge" (Bierly, Daly 2002: 287). More critical is, instead, meeting to share existing knowledge among organizational members since: "the need for exploiter employees to communicate openly, understand each other's area of expertise, and share knowledge in order to consistently and incrementally enhance the existing knowledge base" (Bierly, Daly 2002: 287). The knowledge-exploitation strategy is more likely to maximize profits in the short term, because its returns are less remote in time, less distant from the initial status quo of the firm, and more certain (March 1991; Spender 1992).

Firms that adopt a knowledge-exploration strategy are likely to find that they suffer the costs of experimentation without gaining many of its benefits. The risk of excessive exploration is failure to harvest the value of any single discovery. Conversely, firms that adopt a knowledge-exploitation strategy are likely to find themselves experts in areas that customers no longer value. The risk in excessive exploitation is obsolescence in a changing environment. As a result, both exploration and exploitation are essential for economic organizations. However, according to Levinthal and March (1993), few firms are successful at combining knowledge exploration and knowledge exploitation simultaneously, primarily owing to limited resources within the organization. Therefore, especially in SFs, knowledge exploration and knowledge exploitation are imperfect substitutes, because they often require very different types of organizational cultures, skills, and structures. Also, as argued by Bierly and Daly (2007a), SFs: "are typically more resource constrained and have less organizational slack than large firms, and therefore face greater challenges in developing a knowledge base while managing the tensions and trade-offs associated with exploration and exploitation."

The choice to focus more on either exploration or exploitation strategy has been referred, traditionally and implicitly, to the firm's internal knowledge sources (employees, databases, etc.). Nevertheless, the knowledge-based view of the firm suggests narrowing the firm's internal knowledge base, focusing on core competencies, and relying more on external knowledge sources (customers, suppliers, etc.) to complement its internal strengths. Knowledge created within the firm is especially valuable because it tends to be unique, specific, and tacitly held, thus more difficult for competitors to imitate (Zack 1999). In contrast, knowledge acquired from outside the firm, while more widely available to competitors, can provide fresh thinking and a context for benchmarking internal knowledge, especially to avoid the "reinventing the wheel".

To exploit external knowledge, organizations should acquire contextual knowledge, interacting primarily with knowledge sources that are in close geographical, organizational and technological proximity, such as suppliers, customers, competitors, industrial and technology districts, and professional associations. The shorter the geographical and organizational distance between actors, the easier the possibility to exchange tacit knowledge, and thus learning by interacting via generic meetings, site visits, exter- 
nal training and collaborative learning. The shorter the technological distance between actors, the easier the capacity to absorb technological knowledge. As a result of the importance of learning by imitation, to exploit competitors' knowledge (Maskell, Malmberg 1999), benchmarking should be the primary organizational arrangement to acquire external knowledge. In contrast, in order to explore external knowledge, organizations should also acquire non-contextual and complementary knowledge, by interacting with knowledge sources that are not in close proximity, such as technical and professional institutes, credit and territorial institutes, chambers of commerce. Since firms need to be distant enough from knowledge bases to create new radical knowledge, external knowledge explorers should also rely on third-party tutoring and cooperative research.

With special reference to SFs, Chen et al. (2006) argued that they have strong needs for external knowledge sources, because of their internal resource constraints (time, qualified staff, etc.). On the other hand, their lack of absorptive capacity - "the ability to recognize the value of new information, assimilate it, and apply it to commercial ends" (Cohen, Levinthal 1990: 128) - reduces its potential value. Bierly and Daly argue that: "In theory, limited resources would encourage these small businesses to focus on internal learning to develop the primary capabilities most obviously tied to competitive advantage, and encourage them to rely on external learning to develop secondary capabilities" (2007b: 47).

However, knowledge strategy is not confined to the strategic choice regarding whether to explore or to exploit the internal knowledge, but also includes the strategic choice regarding whether to explore or exploit the external knowledge. In other terms, the knowledge strategy trade-off could be articulated as follows: (1) exploration strategy of internal knowledge vs. exploitation strategy of internal knowledge; (2) exploration strategy of external knowledge vs. exploitation strategy of external knowledge. The two strategic choices are probably related so firms that adopt an exploration strategy of internal knowledge would adopt an exploration strategy of external knowledge, and firms that adopt an exploitation strategy of internal knowledge would adopt an exploitation strategy of external knowledge.

\section{Alignment of knowledge strategies with competitive strategies}

A firm's competitive strategy should define ways to compete within a chosen industry, and, in the market-based view of the firm (Porter 1980) should be established by identifying a desired product/market positioning, and thus the resources required to develop the needed positions of competitive advantage (e.g. product innovation, quality and price). In a resource-based view (Barney 2001; Barney et al. 2001), such ways should be defined, starting with the identification of the firm's unique, valuable, rare and inimitable resources, and thus the product/market positioning that these sources of competitive advantage support (e.g. owner-manager's experience and skills, organizational culture, relationships with customers $)^{1}$. In other words, a firm's desired competitive position

\footnotetext{
${ }^{1}$ Day and Wensley (1988) argue that the sources of competitive advantage should be distinguished from the positions of competitive advantage that, in turn, determine the performance outcomes of competitive advantage.
} 
creates resource requirements, while currently owned or controlled resources create opportunities and constraints for selecting viable competitive positions.

However, market-based and resource-based views of the firm are not in conflict. Authors suggest that these two perspectives have been judged by their a priori validity and by their power to explain parts of the behaviour of firms - hence they are partial models, and that a knowledge-based view can help to integrate the two perspectives. According to a knowledge-based view, the most unique and inimitable resource is the knowledge a firm has about how to combine and coordinate its "traditional" resources, in ways that are new and distinctive (sources of competitive advantage), thus providing products in ways that are superior to those of competitors (positions of competitive advantage), even if its "traditional" resources are not unique and inimitable (Nonaka 1994; Grant 1996; Spender 1996). Knowledge management, then, can be considered as one of the most important dynamic capabilities.

Therefore, knowledge management and, in particular, knowledge strategy, must be properly driven by the firm's competitive strategy. Zack argues that:

"In many firms, knowledge management efforts are divorced from strategic planning and execution. However, having an appropriate knowledge strategy in place is essential for assuring that knowledge management efforts are being driven by and are supporting the firm's competitive strategy" (Zack 1999: 134).

In general terms, the author suggests that a knowledge exploration strategy is more appropriate when the competitive environment changes very rapidly, when the main competitors possess superior knowledge and, overall, when the firm's competitive strategy requires new radical knowledge to be executed. In contrast, a knowledge exploitation strategy is more appropriate when the firm's knowledge base significantly exceeds the requirements of its competitive strategy. More precisely, O'Dell et al. (1998) point out that a knowledge strategy should be driven by one of the three competitive strategies identified by Treacy and Wiersema (1993): i.e. product leadership, operation excellence, and customer intimacy. Since Miller, Bierly and Daly (2007) argue that: "explorers ..., are creative in improving product technologies, and have established new product development processes that enhance their ability to bring new products to market quickly", we do expect that a knowledge-exploration strategy is coherent with a product leadership competitive strategy. In contrast, since: "exploiters should invest more in new process technologies to reduce their cost structure, and excel at practices that facilitate customer satisfaction" (Miller et al. 2007), we do expect that a knowledge exploitation strategy is coherent with operational excellence or a customer intimacy competitive strategy.

Coherent with the initial distinction between the different views of the firm, Smith and McKeen (2003) point out that a knowledge strategy should be driven by a competitive strategy, as capability (resource-based view) or position (market-based view). According to the authors, firms that agree to the former view should adopt a knowledge-exploration strategy, to provide the knowledge creation capacities needed to support: value innovation in products, services, processes and structures; environmental scanning, to identify new customer groups, needs, technologies and materials; or strategic experimentation, 
to create new knowledge about markets, proposed strategies and process changes. On the other hand, firms that agree to the latter view, should adopt a knowledge-exploitation strategy, to support urgent business needs, that can be related mainly to productivity or performance improvement, especially in the area of customer service quality

\section{Alignment of knowledge strategies with competitive strategies in SFs}

Although the extant literature on the alignment of knowledge strategies with competitive strategies provides general arguments that are assumed to fit all kinds of economic organizations, we believe that they can be hardly generalized for SFs. The reason is twofold.

First, most medium and large firms do not succeed in aligning knowledge strategies and competitive strategies because the personnel responsible for the former rarely interact with those personnel responsible for the latter, and vice versa (Zack 2002). Only if a knowledge strategist understands the competitive role of knowledge, can they give a competitive focus to their knowledge management initiatives. At the same time, only if competitive strategist understand the competitive role of knowledge, they can include it in their competitive strategic decision-making (Zack 2005). In SFs, decisions about knowledge strategies and competitive strategies are taken by a single person, i.e. the owner-manager (Feltham et al. 2005). This would suggest that, contrary to what has been suggested by the extant literature, in the context of medium and large firms (Zack 2002), SFs are more likely to align these two types of strategies.

Second, the previously mentioned theoretical perspectives on the alignment of knowledge strategies with competitive strategies are built on case studies analyzing medium or large firms (Halawi et al. 2006; Hansen et al. 1999; Zack 1999). However, Bierly and Daly (2007a: 494) remark that small and large firms build their competitive advantage following different competitive strategies, implying the development of different knowledge strategies. First of all, given the SFs' limited resources, of the three generic competitive strategies proposed by Porter (1980), it appears that only the focus strategy is applicable to them (Lee et al. 1999).

Moreover, a limited set of elements of the value proposition (i.e. number of product lines and variety of products within the line, product innovation, product and pre-/ post-sale customer service quality, price) emerged as possible positions of competitive advantage for SFs (Man et al. 2002). However, the most important ones are product and pre/post-sale customer service quality (Bamberger 1989; O'Donnell et al. 2002). Most of the SFs seem very reluctant to only compete on price, and innovation focused upon new marketing methods, where the product remains more or less the same (Stokes 1995). Thus, the competitive strategy as position (previously proposed by Smith, McKeen 2003), in SFs seems to be based mainly on product and customer service quality (PCSQ).

Also, a limited set of tangible (i.e. fixtures and fittings) and intangible resources (i.e. owner-manager and staff experience and skills, organizational procedures and culture, relationships with potential and current customers) emerged as possible sources of competitive advantage for SFs (Man et al. 2002). Overall, the most important ones are the 
owner-manager's and staff's experience and skills, and their ability to relate to current and potential customers (Man et al. 2002; O'Donnell et al. 2002; Stoner 1987). Experiential learning was regarded as a key enabler of these sources of competitive advantage (Carson 1985). Thus, the competitive strategy as capabilities (previously proposed by Smith, McKeen 2003), in SFs seems to be based mainly on human resources (HR).

Given the aforementioned specificities, how should the two broad perspectives on the alignment of knowledge strategy with competitive strategy, previously proposed by Smith and McKeen (2003), be reframed in the specific context of SFs? In the following section, we develop hypotheses based on this research question.

\section{Hypotheses}

\subsection{Alignment of internal knowledge strategies with competitive strategies in SFs}

SFs adopting HR-based competitive strategies rely generally on their most idiosyncratic and difficult-to-imitate resources, emphasizing the SFs' traditional basis of competition. Since they aim to exploit the complex, specialized, tacit knowledge that is rooted in owner-managers' and staff's experience, which shows itself as skills, they are focused: "on ideas of local search and the evolution of relatively stable organizational routines. Such routines reflect experiential wisdom in that they are the outcome of trial and error learning" (Gavetti, Levinthal 2000: 113). Therefore, we argue that their internal knowledge strategies are focused mainly on incremental experiential learning, which offers a form of backward-looking wisdom, leveraging existing but underexploited knowledge primarily through social (person-to-person) interaction. We reason that they seem to exhibit a passive (i.e. single-loop, lower level, adaptive, incremental) learning orientation (Chaston et al. 2001; Sadler-Smith et al. 2001), which involves the deployment of existing knowledge to improve the efficiency of current activities. Thus, in contrast with the perspective proposed by Smith and McKeen (2003), we expect that SFs adopting HR-based competitive strategies are likely to pursue exploitation strategies of internal knowledge.

SFs adopting PCSQ-based competitive strategies go beyond the SFs' traditional basis of competition. Since they also aim to explore the market opportunities (Pelham 1999), they are more focused on the rational search mode, which is a forward-looking form of evaluation of a broad set of alternatives, that could differ substantially from current behavior (Gavetti, Levinthal 2000). Therefore, we argue that their internal knowledge strategies are more focused on radical strategic learning, "which allows a firm to evaluate, distribute, and integrate exploratory knowledge" (Sirén et al. 2012: 19), by formalizing this knowledge to make it available to all the organizational members. In SFs, socialization dominates all other knowledge generation activity modes (Desouza, Awazu 2006). Nevertheless, Gray (2006) recognizes the crucial role of formalization:

"The drawing together of experiential knowledge of key employees (including the owner-manager) and the making explicit the effective routines developed within the firm in order to share, combine knowledge and create new knowledge is the innovative process that lies at the heart of KM" (Gray 2006). 
We argue that SFs adopting PCSQ-based competitive strategies seem to exhibit an active (i.e. double-loop, higher level, generative, transformational) learning orientation (Slater, Narver 1995), which involves the development of new knowledge to improve the effectiveness of novel activities. Thus, in contrast with the perspective proposed by Smith and McKeen (2003), we expect that SFs adopting PCSQ-based competitive strategies are likely to pursue exploration strategies of internal knowledge.

The above lines of logic lead to the following hypotheses:

H1: In SFs, there is alignment between competitive strategies and internal knowledge strategies.

H1a: In SFs, there is alignment between HR-based competitive strategies and exploitation strategies of internal knowledge.

H1b: In SFs, there is alignment between PCSQ-based competitive strategies and exploration strategies of internal knowledge.

\subsection{Alignment of external knowledge strategies with competitive strategies in SFs}

Since SFs that focus on ideas of local searching would prefer to have frequent relations only with external knowledge sources that are in close geographical, organizational and technological proximity, we argue that the external learning processes that characterize SFs' adoption of HR-based competitive strategies are learning by (local) interaction, and learning by imitation. Learning by interaction is based principally on the continuous exchange of knowledge among firms and customers, and among firms and suppliers. In learning by imitation, different knowledge channels can be used, such as the consultation of industrial and technology districts, and professional associations' knowledge bases, as well as the benchmarking analysis of competitors (Petruzzelli et al. 2007). Therefore, their external knowledge strategies are expected to be mainly incremental, acquiring information from the external environment only to refine their current activities, and not to create radical new knowledge. In other words, in contrast with the perspective proposed by Smith and McKeen (2003), we expect that SFs adopting HR-based competitive strategies are likely to pursue exploitation strategies of external knowledge.

Since SFs that focus on ideas of rational searching also tend to create competitive advantage, through iterative, cumulative and cooperative relationships with external knowledge sources, that are not necessarily in close geographical, organizational and technological proximity (Morgan et al. 1998), we argue that the external learning processes that characterize SFs adopting PCSQ-based competitive strategies are, therefore, also based on "strong" interfirm linkages that involve substantial knowledge-sharing, and the combination of complementary resources:

"The emphasis is on increasing the scope and depth of knowledge by refining what is known and by bringing in additional expertise relevant for knowledge creation. Some of this expertise could come from partner firms, or partner firms could provide data, information and knowledge in order to fuel the knowledge creation process. ... R\&D as well as market research are key activities to facilitate expansion of the domain" (von Krogh et al. 2001). 
Therefore, their knowledge acquisition strategies are expected to be mainly radical, acquiring information from a wide-ranging and varied external network. In other words, in contrast with the perspective proposed by Smith and McKeen (2003), we expect that SFs adopting PCSQ-based competitive strategies are likely to pursue exploration strategies of external knowledge.

The above lines of logic lead to the following hypotheses:

H2: In SFs, there is alignment between competitive strategies and external knowledge strategies.

H2a: In SFs, there is alignment between HR-based competitive strategies and exploitation strategies of external knowledge.

H2b: In SFs, there is alignment between PCSQ-based competitive strategies and exploration strategies of external knowledge.

Our overall theoretical framework is shown in Table 1.

Table 1. Theoretical framework: knowledge strategy and competitive strategy alignment in SFs

\begin{tabular}{llcccc}
\hline & \multicolumn{4}{c}{ Knowledge strategies } \\
\hline & \multicolumn{4}{c}{ Internal knowledge strategies } & External knowledge strategies \\
\hline & Exploitation & Exploration & Exploitation & Exploration \\
\hline \multirow{2}{*}{$\begin{array}{l}\text { Competitive } \\
\text { strategies }\end{array}$} & $\begin{array}{l}\text { Human } \\
\text { resource-based }\end{array}$ & H1a & & H2a & \\
\cline { 2 - 6 } & $\begin{array}{l}\text { Product and } \\
\text { customer service } \\
\text { quality-based }\end{array}$ & & $\mathrm{H} 1 \mathrm{~b}$ & & $\mathrm{H} 2 \mathrm{~b}$ \\
\hline
\end{tabular}

\section{Methodology}

\subsection{Sample and setting}

The present study was carried out in 2004, on a sample of SFs (fewer than 50 employees) situated in the northeast Italy. Through cooperation with local SF associations, which provided company names and contacts, 100 potential participants were selected ${ }^{2}$. Initial contact was made by phone, to carry out preliminary discussions with ownermanagers regarding the study aims and, therefore, to identify those willing to take part in the study. The phone calls resulted in 57 SFs from various industries agreeing to participate (Annex 1), but 1 firm was subsequently eliminated owing to incomplete data ${ }^{3}$. The vast majority of effective participants are very small (having on average fewer

${ }^{2}$ Participants were not selected on the basis of their representativeness of the broader population. Rather, the selection was based on the SFs' potential interest in, and willingness to participate in the study, in order to obtain information as far as possible.

${ }^{3}$ A 57\% response rate is close to those obtained in similar research projects (e.g. Choi, Lee 2003). 
than 15 employees), and relatively young firms (more than 5 years but, on average, less than 30 years old) ${ }^{4}$. Power is almost always highly centralized in the hands of 1 or 2 members of the owner's family. Nearly all the firms operate in mature industries.

The data were gathered by means of face-to-face, semi-structured (i.e. closed questions, closed and open answers), in-depth interviews with the owner-managers, and carried out by two research assistants. The questionnaire framework was structured in four sections: 1) the firm's general information; 2) the firm's historical evolution; 3) the firm's competitive strategy; 4) the firm's knowledge strategies. A sample of the interview questions related to, for example, external knowledge strategies is as follows: What are the most important external knowledge sources? What are the most relevant mechanisms used to acquire external knowledge? Can you give some examples of knowledge acquisition mechanisms? The questionnaire's framework, comprehensibility and completeness were tested by pilot interviews in two firms, carried out by the authors, and by the two research assistants involved in the data collection.

A total of 114 four-hour interviews were carried out ( 2 interviews per firm). During the interviews, the informants were encouraged to ask questions about the study aims, and to make sure that the meanings - especially of the open questions included in the questionnaire - were absolutely clear. Cluster analyses were used to classify the firms into different competitive strategy groups, internal knowledge strategy groups and external knowledge strategy groups. To investigate the link between competitive strategies and knowledge strategies, independence among all the above mentioned groups was tested by computing a chi-square test $\left(\chi^{2}\right)$ (Hair et al. 1998). Details on variables and descriptive statistics are reported in Annexes 1-4.

\subsection{Variables and analysis procedures}

\section{Competitive strategy groups}

A two-stage process was undertaken to identify the competitive strategy groups. First, content analysis of the narrative information gathered was performed separately by the two research assistants involved in the data collection, and by three additional research assistants. They analyzed the transcripts and the notes according to a categorical analysis, in order to provide a superordinate list of the competitive advantages identified by the informants. Subsequently, a cluster analysis was performed to classify the firms in the sample into different groups, based on their competitive advantages. During the initial readings of the transcriptions and the notes, they identified numerous first-order concepts. They devoted subsequent readings to assembling these concepts into categories that defined similar competitive advantages. Next, they used a form of constant comparison to triangulate comparative data from different informants, to discern the shared concepts. They developed comprehensive cross-reference lists to keep track of

\footnotetext{
${ }^{4}$ Only firms that have proven strategic fit survive to the selection phase: “... 60 to 80 percent of new businesses fail in their first five years of operation. So a SME that has survived for more than five years is most probably doing something right, amongst them undertaking a viable approach to managing knowledge" (Delahaye 2005: 604).
} 
category commonality. Next, they focused on convergent concepts and their relation to the evolving categories that emerged initially. On the basis of this analysis, they merged some overlapping categories. Then they assigned second-order, theoretical labels to the emergent competitive advantages. They used these second-order concepts to capture the informant categories at a higher level of abstraction. They derived these labels either by developing a more general label, that subsumed the first-order concepts, or by reference to the existing literature that described the emergent concepts well. They then conducted a final iteration of constant comparison to decide whether enough evidence existed to support an identified concept as a reportable finding.

Finally, they assembled the second-order concepts into aggregate analytical dimensions that provided a superordinate list of the competitive advantages, identified by the owner-managers interviewed. The informants identified both sources of competitive advantage (e.g. owner-manager's experiences) and positions of competitive advantage (e.g. product quality). The superordinate list of the competitive advantages identified was then analyzed by the authors, with the purpose of validating the qualitative analysis conducted by the five research assistants, and resolving cases of non-convergence.

The final list consists of 14 diverse items: 7 regarding positions of competitive advantage; and 7 regarding sources of competitive advantage (Annex 2). These items represent a subset of the "classical" competitive advantages, recognized in the strategic management literature (Aaker 1989). For each of these items above, and for each of the firms in the sample, the research assistants specified - using a dummy variable whether (1) or not (0) the owner-manager interviewed identified the related competitive advantage position or source.

Cluster analyses, which were used to classify the firms into different groups, based on their competitive advantage positions and sources, were carried out using SPSS 13.0 for Windows. Specifically, we chose Ward's hierarchical technique of clustering, using squared Euclidean distances. This technique has been applied by other authors (Bierly, Chakrabarti 1996; De Pablos 2002; Choi, Lee 2002, 2003). It is also the most frequently used in research conducted on strategic management (Ketchen, Shook 1996) 5 .

\section{Internal and external knowledge strategy groups}

The same two-stage process previously mentioned was also undertaken to identify the internal and external knowledge strategy groups. Content analysis, which was used to provide a super-ordinate list of the knowledge creation or acquisition activity types identified by the informants, was performed using the same procedure mentioned above.

\footnotetext{
${ }^{5}$ The decision concerning how many clusters to use was guided by a visual inspection of the dendogram (i.e. a graph of the order in which observations join clusters, and the similarity of observations joined), and confirmed by the agglomeration schedule (i.e. a numerical value that displays the Euclidean distances between each case or group of cases combined, to form a cluster for each step of the process). In the first case, we looked for natural clusters of the data that were indicated by relatively dense "branches". In the second case, we examined the incremental changes in the coefficient. A large increase implied that dissimilar clusters were the result of a merger; thus, the number of clusters prior to the merger is the most appropriate.
} 
Consistent with the questionnaire framework, the activity types within a class result in a combination of the following aspects:

- "where" the knowledge is created and acquired; and

- "how" such knowledge is created and acquired.

The final list consists of the following items (Annexes 3 and 4):

- 14 different ways of creating knowledge (6 "where" +8 "how");

- 14 different ways of acquiring knowledge (7 "where" +7 "how").

In addition, cluster analyses, which were used to classify the firms into different groups based on their knowledge activity types, were carried out using the same technique mentioned previously.

The relationship between competitive strategy groups and internal and external knowledge strategy groups

To investigate the link between competitive strategies and knowledge strategies the groups identified at the level of competitive strategy, as well as at the level of internal knowledge strategy and of external knowledge strategy, were taken into account. In view of the fact that all the variables above are nominal, their independence was tested by computing a chi-square test $\left(\chi^{2}\right)$. The $\chi^{2}$ test tabulates a variable into categories, and computes a $\chi^{2}$ statistic. This goodness-of-fit test compares the observed and expected frequencies in each category, to test whether all the categories contain the same proportion of values, or whether each category contains a user-specified proportion of values. Given that the $\chi^{2}$ test requires a large number of samples, contingency coefficients and Cramer's Pi and V were also computed to confirm independence further. The following measures were also calculated based on the principle of "predictional reduction in error": $\lambda$ and the uncertainty coefficient.

\section{Results}

\subsection{Competitive strategy groups}

Consistent with the extant literature, the cluster analysis led to the identification of two groups of firms at the level of competitive strategy (Annex 2).

\section{Group 1: HR-based competitive strategy}

Few firms belonging to this group identify number of product lines (14\%), variety within a product line $(3 \%)$, and price $(14 \%)$, as well as product quality $(34 \%)$, as positions of competitive advantage. Nevertheless, the majority of them identify pre-sales $(55 \%)$ and post-sales $(62 \%)$ customer service quality as positions of competitive advantage. Almost all the firms identify the owner-manager's (100\%) and staff members' (97\%) experience and skills as sources of competitive advantage. Moreover, many firms also identify relationship with potential (48\%) and current (34\%) customers, fixture and fittings (34\%), and organizational procedures (31\%) as sources of competitive advantage. These firms emphasize a resource-based view, adopting a competitive strategy focused on human resources. They rely on their most idiosyncratic and difficult-to-imitate assets that allow them to maintain personal contact with customers, which is usually considered the key 
component of customer service quality. They emphasize the SFs' traditional basis of competition, paying more attention to internal/organizational strengths.

\section{Group 2: PCSQ-based competitive strategy}

With respect to firms in Group 1, a higher percentage of firms belonging to this group identifies number of product lines $(30 \%)$, variety within a product line $(19 \%)$ price $(33 \%)$, as well as product quality $(67 \%)$, pre-sales $(52 \%)$ and post-sales $(55 \%)$ customer service quality as positions of competitive advantage. In contrast, a smaller percentage of firms identifies the owner-manager's (33\%) and staff members' $(0 \%)$ experience and skills, as well as the relationship with potential (41\%) and current $(22 \%)$ customers, fixture and fittings (15\%) and organizational procedures $(26 \%)$ as sources of competitive advantage. These firms emphasize a market-based view, adopting a competitive strategy focused on Product and customer service quality. They go beyond the SFs' traditional basis of competition, paying more attention to external/environmental opportunities.

\subsection{Knowledge strategy groups}

\section{Internal knowledge strategy groups}

Consistent with the extant literature, the cluster analysis led to the identification of two groups of firms at the level of internal knowledge strategy (Annex 3).

\section{Group 1: Exploitation strategy of internal knowledge}

Few firms belonging to this group rely on organizational members' job description (14\%) and competence balance sheet $(9 \%)$, as well as on paper $(50 \%)$ and an electronic $(5 \%)$ database. Thus, in these firms, knowledge is spread among the organizational members, and is neither easily nor readily identifiable. Experienced organizational members not in charge of $R \& D$ activities (100\%) are the primary source of improvements, based on tacit knowledge. Therefore, internal training (45\%), as well as formalization and diffusion of best practices (36\%), are less common than a meeting, to share existing knowledge among organizational members $(82 \%)$. None of the firms rely on organizational members in charge of R\&D activities and, thus, on planned designed experimentation. Only a few firms rely on occasional designed experimentation (36\%). By contrast, they emphasize learning "by doing”, and thus on-the-job individual experimentation (100\%), and emphasize the incremental enhancement of existing knowledge.

\section{Group 2: Exploration strategy of internal knowledge}

With respect to firms in Group 1, a higher percentage of firms belonging to this group relies on organizational members' job description (59\%) and competence balance sheet (26\%), as well as on paper and an electronic database to formalize and diffuse best practices (79\%). Thus, in these firms, knowledge is stored not only in the heads of organizational members, but also in codified repositories that allow the use of impersonal sharing mechanisms. The vast majority of these firms rely on organizational members not in charge of R\&D activities (94\%), encouraging on-the-job individual experimentation (88\%) and occasional designed experimentation (85\%). More than a quarter of them also rely on organizational members in charge of R\&D activities (26\%), developing planned designed experimentation (36\%). Also, the vast majority organize internal 
training (97\%) and meetings to share existing (68\%) and new (74\%) knowledge among organizational members. They emphasize not only the incremental enhancement of the existing knowledge, but also the creation of radical new knowledge.

\section{External knowledge strategy groups}

Consistent with the extant literature, the cluster analysis led to the identification of two groups of firms at the level of external knowledge strategy (Annex 4).

\section{Group 1: Exploitation strategy of external knowledge}

Almost all the firms belonging to this group have a focused external network. They acquire mainly contextual knowledge, interacting primarily with knowledge sources that are in close geographical, organizational and technological proximity, such as suppliers $(94 \%)$, customers $(92 \%)$, competitors $(92 \%)$, industrial and technology districts, and professional associations (94\%). The shorter the distance between actors, the easier the possibility to exchange tacit knowledge, and thus learning by interacting via generic meetings $(50 \%)$, site visits $(50 \%)$ and external collaborative learning (58\%). The vast majority of these firms rely on benchmarking $(69 \%)$, owing to the importance of learning by imitation to exploit competitors' knowledge. They deploy existing external knowledge to improve the efficiency of current activities, using knowledge acquisition mechanisms that require low degrees of interaction with external knowledge sources.

\section{Group 2: Exploration strategy of external knowledge}

With respect to firms in Group 1, the majority of the firms belonging to this group have a wide-ranging and varied external network. They also acquire non-contextual and complementary knowledge, interacting with knowledge sources that are not in close geographical, organizational and technological proximity, such as technical and professional institutes $(60 \%)$, credit and territorial institutes (50\%), and chambers of commerce $(50 \%)$. Since actors need to be distant enough to create new radical knowledge, the vast majority of these firms also adopt those knowledge acquisition mechanisms that imply a higher degree of interaction with external heterogeneous networks, such as third-party tutoring (65\%), external training (85\%), and cooperative research $(70 \%)$. They also develop new knowledge to improve the effectiveness of novel activities, building lasting relationships with external knowledge sources.

\subsection{Alignment of knowledge strategies with competitive strategies in SFs: statistics}

The hypotheses are tested with cross-tabulations between knowledge strategies and competitive strategies. As shown in Table 2, in the various combinations of internal knowledge strategies and competitive strategies the observed frequencies are higher than the expected frequencies in the combinations HR-based competitive strategies and exploitation strategies of internal knowledge, and PSCQ-based competitive strategies and exploration strategies of internal knowledge. If the differences between the observed and expected frequencies are significant, these results would provide support for hypotheses 1a and 1b, respectively. Similarly, in Table 3, in the various combinations of external knowledge strategies and competitive strategies, the observed frequencies are 
higher than the expected frequencies in the combinations HR-based competitive strategies and exploitation strategies of external knowledge, and PSCQ-based competitive strategies and exploration strategies of external knowledge. If the differences between the observed and expected frequencies are significant, these results will provide support for hypotheses $2 \mathrm{a}$ and $2 \mathrm{~b}$, respectively.

To check whether the differences between the observed and the expected frequencies are significant, we have computed a $\chi^{2}$ statistic. This statistic (Table 4 ) shows that a very significant relationship exists between internal knowledge strategy groups and competitive strategy groups $(\beta=3.901 ; p<.05)$, as well as between the external knowledge strategy groups and competitive strategy groups $(\beta=5.914 ; p<.05)$, thus providing support for hypotheses $1 \mathrm{a}$ and $1 \mathrm{~b}$, respectively, as well as for hypotheses $2 \mathrm{a}$ and $2 \mathrm{~b}$.

Table 2. Cross-tabulation between internal knowledge strategy groups and competitive strategy groups

\begin{tabular}{rlccc}
\hline & & \multicolumn{2}{c}{ Internal knowledge strategies } & \\
\cline { 2 - 5 } & & Exploitation & Exploration & Total \\
\hline \multirow{2}{*}{ Competitive strategies } & HR-based & $15(11.4)$ & $14(17.6)$ & 29 \\
\cline { 2 - 5 } & PCSQ-based & $7(10.6)$ & $20(16.4)$ & 27 \\
\hline Total & 22 & 34 & 56 \\
\hline
\end{tabular}

Note: Expected frequencies in brackets.

Table 3. Cross-tabulation between external knowledge strategy groups and competitive strategy groups

\begin{tabular}{llccc}
\hline & & \multicolumn{2}{c}{ External knowledge strategies } & \\
\cline { 3 - 5 } & & Exploitation & Exploration & Total \\
\hline $\begin{array}{l}\text { Competitive } \\
\text { strategies }\end{array}$ & HR-based & $23(18.6)$ & $6(10.4)$ & 29 \\
\cline { 2 - 5 } & PCSQ-based & $13(17.4)$ & $14(9.6)$ & 27 \\
\hline Total & 36 & 20 & 56 \\
\hline
\end{tabular}

Note: Expected frequencies in brackets.

Table 4. $\chi^{2}$ test results between knowledge strategy groups and competitive strategy groups

\begin{tabular}{lccc}
\hline & \multicolumn{3}{c}{ Pearson chi-square } \\
\cline { 2 - 4 } Relationships between: & $\begin{array}{c}\text { Value } \\
(\beta)\end{array}$ & Df & $\begin{array}{c}\text { Asy. sig. } \\
\text { (2-sided) }\end{array}$ \\
\hline Internal knowledge strategy groups and competitive strategy groups & 3.901 & 1 & $0.044^{*}$ \\
\hline External knowledge strategy groups and competitive strategy groups & 5.914 & 1 & $0.015^{*}$ \\
\hline
\end{tabular}

Notes: significance: ${ }^{* *} p<.001 ; * *<.01 ;{ }^{*} p<.05 ; \dagger p<.10$; Df $=$ degree of freedom. 


\section{Discussions}

Our findings reveal that there is an alignment between knowledge strategies and competitive strategies in SFs. Since the extant literature suggests that this alignment is particularly weak in larger firms (Zack 2002), our findings confirm that the knowledge strategy and competitive strategy fit seems to be more present in economic organizations where there is close alignment between those responsible for the knowledge strategy and those responsible for the competitive strategy. In SFs, this alignment is maximal since they are characterized by the presence of only one key strategic decision-maker: the owner-manager. The owner-manager understands perfectly the competitive role of knowledge, especially if their head is the firm's most critical knowledge repository. Therefore they can include (their) knowledge in their competitive strategic decisionmaking, giving a competitive focus to the firm's knowledge management initiatives.

Most medium and large firms do not succeed in aligning knowledge strategies and competitive strategies, because the personnel responsible for competitive strategy rarely interact with the personnel responsible for knowledge strategy, and vice versa. This is especially true for larger firms that pursue exploration and exploitation, conceiving these knowledge strategies simultaneously, not as substitutes, but as complements (He, Wong 2004; Ichijo 2002; Knott 2002). In fact, to succeed as "ambidextrous" organization a firm needs a complex organizational structure (Tushman, O’Reilly 1996). Nevertheless, the presence of a complex organizational structure makes more difficult to succeed in aligning (exploitation-exploration) knowledge strategy with competitive strategy. This misalignment could explain why the strategic choice to pursue simultaneously exploration and exploitation seems not to increase firm performance (Bierly, Daly 2007a).

In particular, in analyzing the alignment between SFs' competitive strategies and knowledge strategies, consistent with the extant literature, we have identified two types of competitive strategies pursued by SFs, i.e. human resource-based (HR-based), and product and customer quality-based (PCSQ-based). Although the resource-based and the market-based views of the firm are complementary perspectives, SFs seem explicitly or implicitly, consciously or unconsciously, to only emphasize a single perspective. We have also identified two types of internal knowledge strategy, i.e. exploitation strategy of internal knowledge and exploration strategy of internal knowledge, and two types of external knowledge strategy, i.e. exploitation strategy of external knowledge and exploration strategy of external knowledge. Our findings reveal that SFs pursuing HR-based competitive strategies tend to adopt exploitation strategies of both internal (H1a) and external knowledge (H1b), while firms pursuing PCSQ-based competitive strategies tend to adopt exploration strategies of both internal $(\mathrm{H} 2 \mathrm{a})$ and external knowledge $(\mathrm{H} 2 \mathrm{~b})$.

These findings contribute to the knowledge-management literature, investigating which knowledge strategies should be adopted by SFs. For example, Chen et al. (2006) argue that SFs have very strong need of external knowledge and interfirm knowledge transfer, because of their internal resource constraints (time, qualified staff, etc.). In contrast, Bierly and Daly (2007b) argue that the lack of substantial in-house capacity to recognize, evaluate, negotiate and, finally, adapt the knowledge available from external sources - 
especially if they are not in close geographical, organizational and technological proximity, such as suppliers, customers and competitors - reduces its potential strategic value. Thus, the authors argue that, for SFs, the competitive advantage would rely on extending their capabilities of leveraging internal knowledge, rather than on extending linkages with heterogeneous external sources of knowledge: “... limited resources would encourage these small businesses to focus on internal learning to develop the primary capabilities most obviously tied to competitive advantage, and encourage them to rely on external learning to develop secondary capabilities" (Bierly, Daly 2007b). Our findings affirm that, in SFs, the focus on the external knowledge sources depend on the competitive strategy adopted.

These findings also contribute to the extant literature by offering different perspectives on the alignment of knowledge strategies with competitive strategies, proposed in the extant literature. Smith and McKeen (2003: 2) argue that firms adopting a more "traditional and static" market-based competitive strategy (i.e. strategy as position in the market place) should adopt an exploitation strategy of internal and external knowledge. In contrast, firms adopting a "more dynamic and disorganized" resource-based competitive strategy (i.e. strategy as capabilities) “... emphasizing a new set of strategic imperatives, such as flexibility, continuous improvement and the development of core competencies" (Smith, McKeen 2003: 2) should adopt an exploration strategy of internal and external knowledge.

The fact that our findings contrast with results of the extant literature might be owing to the fact that the previously mentioned theoretical perspectives, on the alignment of knowledge strategies with competitive strategies, are built on studies analyzing medium or large firms. Nevertheless, small and medium-large firms build their competitive advantage following different competitive strategies, andcompetitive strategy formulation processes. First of all, given the SFs' limited resources, the adoption of a: “...disorganized approach which emphasizes strategy-making throughout the organization and continuously over time", where, "the result is a semi-coherent direction that emerges over time which is not integrated across the company" (Smith, McKeen 2003: 3), is the rule, not the ambition for SFs. Therefore, for an SF, the challenge is to became more market-oriented, improving their competitive position to create a sustainable competitive advantage.

\section{Conclusions and managerial implications}

The problem of inter-level strategic fit at the core of our study is related strictly to the issues of evolutionary or revolutionary change, since they can be viewed as outputs of an exploitation or exploration strategy knowledge, respectively. Internal fit can lead to a sustainable competitive advantage, because it makes imitation difficult (Rivkin 2000). Conversely, it makes the firm's adaptation to radical external environmental changes more complex, because it requires a simultaneous revision of many activities, and of their modes of interaction. Some authors argue that revolutionary or quantum changes are more effective than evolutionary or piecemeal incremental ones, in facing structural changes (Miller, Friesen 1982). A firm's adaptation to the latter requires, first and 
foremost, a revision of the current modes of cognition, to enable the firm to perceive correctly, and thus to take advantage of, external environmental opportunities, and/or to cope with external environmental threats.

The firm's adaptation to radical external environmental changes requires it to revise the top managers' cognitive representations, which have probably become relatively inaccurate, and/or incomplete bases on which to form their mental models (Barr et al. 1992). Since these cognitive representations are largely unrecognized by the managers themselves, especially by owner-managers with long experience of success, they are generally unable to revise their view of the world. Some scholars make it clear that before "double-loop" learning can occur - the kind of learning needed to accomplish a revolutionary change (Argyris, Schon 1978) - the old representations must first be recognized, and subsequently challenged (Prahalad, Bettis 1995). Recognizing and thus challenging the existing cognitive representations, while important to any firm in the presence of radical external environmental changes, is crucial for SFs in which the owner-managers' mental models (and the derived beliefs about the linkage between the choice of actions and the subsequent impact of those actions on outcomes), that have developed over time, based on their personal experience, are so deeply ingrained that they are taken for granted and, therefore, cannot be easily articulated and discussed.

Recognizing and thus challenging the existing cognitive representations is crucial, especially for SFs adopting an HR-based competitive strategy, since they exhibit a passive learning orientation: they are often embedded in organizational routines imposed by the owner-manager and, therefore, are less likely to pursue strategic changes. They are focused on ideas of incremental experiential learning: semi-automatic organizational routines that prove successful tend to prevail over time, creating a potential for lockin effects, and path dependencies that inhibit strategic changes. On the other hand, in these firms, the impact of cognitive representations on behaviors seems to be limited. Nevertheless, authors claim that they play an important role in seeding and constraining the process of experiential search, and thus, "changing a cognitive representation itself can act as an important mode of adaptation, effectively resulting in the sequential allocation of attention to different facets of the environment" (Gavetti, Levinthal 2000: 113). Conversely, SFs adopting PSCQ-based competitive strategy seem to possess the conceptual skills, and cognitive abilities to support a radical strategic learning. They are more focused on rational searching that is based on owner-managers' explicit consideration of the possible consequences of the choices they make. Since, in these firms, strategy does not only reside in the world of action, the recognition of existing cognitive representations should be easier.

In medium and large firms, the recent affirmation of a knowledge-based view poses the managerial problem of how to align knowledge strategies with competitive strategies. Some scholars stress the importance of connection at top management levels. Others provide a framework to develop a knowledge-based SWOT (strengths-weaknesses-opportunities-threats) analysis. It should support the synchronization between knowledge strategic plans and competitive strategic plans, ensuring that they will work towards the same priorities and time frames. This alignment appears much stronger in SFs. Hence, 
in SFs, especially in those adopting HR-based competitive strategies, the most critical aspect seems to stimulate the possibility of changing competitive strategies in a radical way, allowing radically new knowledge to be generated without losing internal fit. The challenge to SFs' practitioners in strategic (knowledge) management is not to put forward proposals that attempt to demonstrate how to incorporate knowledge concepts into methodologies and tools for the strategy formulation, but to put forward proposals that aim to help owner-managers and, eventually, other key organizational members to review their private sphere of perception of their firm's internal and external environment, in order to improve their revolutionary change capacity.

\section{Limitations and suggestions for future research}

While this study provides several interesting results and insights into the strategic behavior of SFs, it certainly has some limitations. With reference to the sample, all the firms are from a particular geographical area. This constraint precludes the possibility that the firms' differences, at the level of knowledge management activities, could be influenced by socially specific and extra-organizational factors, such as labor markets, policy and provision of workforce training, mechanisms governing the support of business development, attitudes and policy concerned with science and technology, etc. On the other hand, the results' generalizability from this setting to other areas may be questionable. Research encompassing a broader geographic area would be useful for determining whether the findings of this study are consistent with SFs in other parts of Italy, and elsewhere in the world.

Moreover, the firms in the sample are from both the service and the manufacturing sectors, the fundamentals of which, particularly as regards the role of technology, sector development and competitive dynamics, are generally very different. However, nearly all the firms in the sample operate in mature, old technologically based industries, and several of them follow a niche strategy. In these cases, therefore, industry factors do not seem to be significant constraints. Research focused only on service or manufacturing firms would be useful to confirm the findings of this study.

With reference to the methodology, we have examined the fit between knowledge strategies and competitive strategies from a gestalt perspective; that is, a multivariate approach that is free of criteria (i.e. organizational effectiveness and thus organizational performance). This fit approach is coherent with the argument of Smith and McKeen, who argued that: "while performance itself is a useful metric, the ultimate measure of value is the ability to support an organization's competitive strategy. This especially applies to knowledge management, as knowledge has been considered an organization's most strategic resource" (Smith, McKeen 2003: 1). Nevertheless, future research, aimed at investigating how the alignment between knowledge strategies and competitive strategies impact on SFs organizational effectiveness, and thus organizational performance, would be useful to confirm the importance of this alignment.

Moreover, a study conducted by means of a series of structured (i.e. closed questions and closed answers) interviews, and carried out on a larger sample size, might provide more generalizable findings. A larger sample would also allow for the testing of a more 
integrative research model, that involves the simultaneous and joint consideration of SFs' knowledge strategies and competitive strategies, as well as external and internal environmental factors. Finally, this study does not test whether and how the alignment of knowledge strategies and competitive strategies changes over time. A longitudinal study might provide additional insights into conceptualizing this problem of inter-level strategic fit in SFs.

\section{References}

Aaker, D. A. 1989. Managing assets and skills: the key to a sustainable competitive advantage, California Management Review 31(2): 91-106.

Argyris, C.; Schon, D. 1978. Organizational learning: a theory of action perspective. AddisonWesley, Reading MA.

Bagnoli, C.; Roberts, H. 2011. Governing strategy and knowledge: tools and methodologies, Journal of Management \& Governance 17(3): 535-540.

http://dx.doi.org/10.1007/s10997-011-9193-2

Bagnoli, C.; Vedovato, M. 2012. The impact of knowledge management and strategy configuration coherence on SME performance, Journal of Management \& Governance.

http://dx.doi.org/10.1007/s10997-012-9211-z

Bamberger, I. 1989. Developing competitive advantage in small and medium-sized firms, Long Range Planning 22(5): 80-88. http://dx.doi.org/10.1016/0024-6301(89)90172-6

Barney, J. B. 2001. Is the resource-based theory a useful perspective for strategic management research? Yes, Academy of Management Review 26(1): 41-56.

Barney, J. B.; Wright, M.; Ketchen, Jr. D. J. 2001. The resource-based view of the firm: ten years after 1991, Journal of Management 27(6): 625-641. http://dx.doi.org/10.1177/014920630102700601

Barr, P. S.; Stimpert, J. L.; Huff, A. S. 1992. Strategy process: managing corporate self-renewal, Strategic Management Journal 13(Special Issue): 15-36.

http://dx.doi.org/10.1002/smj.4250131004

Bierly, P. E.; Chakrabarti, A. 1996. Generic knowledge strategies in the US pharmaceutical industry, Strategic Management Journal 17(Special issue): 123-135.

Bierly, P.; Daly, P. 2002. Aligning human resource management practices and knowledge strategies, in C. W. Choo, N. Bontis (Eds.). The strategic management of intellectual capital and organizational knowledge. New York: Oxford University Press, 277-295.

Bierly, P. E.; Daly, P. S. 2007a. Alternative knowledge strategies, competitive environment, and organizational performance in small manufacturing firms, Entrepreneurships Theory \& Practice 31(4): 493-516. http://dx.doi.org/10.1111/j.1540-6520.2007.00185.x

Bierly, P. E.; Daly, P. S. 2007b. Sources of external organizational learning in small manufacturing firms, International Journal of Technology Management 38(1/2): 45-68.

http://dx.doi.org/10.1504/IJTM.2007.012429

Carson, D. J. 1985. The evolution of marketing in small firms, European Journal of Marketing 19(5): 7-16. http://dx.doi.org/10.1108/EUM0000000004739

Chaston, I.; Badger, B.; Mangles, T.; Sadler-Smith, E. 2001. Organizational learning style, competencies and learning systems in small, UK manufacturing firms, International Journal of Operation \& Production Management 21(11): 1417-1432.

http://dx.doi.org/10.1108/EUM0000000006224

Chaston, I.; Badger, B.; Sadler-Smith, E. 1999. Organizational learning: research issues and application in SME sector firms, International Journal of Entrepreneurial Behaviour \& Research 5(4): 191-203. http://dx.doi.org/10.1108/13552559910293146 
Chen, S.; Duan, Y.; Edwards, J. S.; Lehaney, B. 2006. Toward understanding inter-organizational knowledge transfer needs in SMEs: insight from a UK investigation, Journal of Knowledge Management 10(3): 6-23. http://dx.doi.org/10.1108/13673270610670821

Choi, B.; Lee, H. 2002. Knowledge management strategy and its link to knowledge creation process, Expert Systems with Applications 23(3): 173-187.

http://dx.doi.org/10.1016/S0957-4174(02)00038-6

Choi, B.; Lee, H. 2003. An empirical investigation of KM styles and their effect on corporate performance, Information \& Management 40(5): 403-417.

http://dx.doi.org/10.1016/S0378-7206(02)00060-5

Clarke, J.; Turner, P. 2004. Global competition and the Australian biotechnology industry: developing a model of SMEs knowledge management strategies, Knowledge and Process Management 11(1): 38-46. http://dx.doi.org/10.1002/kpm.190

Cohen, W. M.; Levinthal, D. A. 1990. Absorptive capacity: a new perspective on learning and innovation, Administrative Science Quarterly 35: 128-152.

Davenport, S. 2005. Exploring the role of proximity in SME knowledge-acquisition, Research Policy 34(5): 683-701. http://dx.doi.org/10.1016/j.respol.2005.03.006

Day, G. S.; Wensley, R. 1988. Assessing advantage: a framework for diagnosing competitive superiority, Journal of Marketing 52(April): 1-20. http://dx.doi.org/10.2307/1251261

De Pablos, P. O. 2002. Knowledge management and organizational learning: typologies of knowledge strategies in the Spanish manufacturing industry from 1995 to 1999, Journal of Knowledge Management 6(1): 52-62. http://dx.doi.org/10.1108/13673270210417691

Dean, T. J.; Brown, R. L.; Bamford, C. E. 1998. Differences in large and small firm responses to environmental context: strategic implications from a comparative analysis of business formations, Strategic Management Journal 19(8): 709-728.

http://dx.doi.org/10.1002/(SICI)1097-0266(199808)19:8<709::AID-SMJ966>3.0.CO;2-9

Delahaye, B. 2005. Knowledge management in a SME, International Journal of Organisational Behaviour 9(3): 604-614.

Desouza, K. C.; Awazu, Y. 2006. Knowledge management at SMEs: five peculiarities, Journal of Knowledge Management 10(1): 32-43. http://dx.doi.org/10.1108/13673270610650085

Drew, S. 1999. Building knowledge management into strategy: making sense of a new perspective, Long Range Planning 32(1): 130-136. http://dx.doi.org/10.1016/S0024-6301(98)00142-3

Ebben, J. J.; Johneson, A. C. 2005. Efficiency, flexibility or both? Evidence linking strategy to performance in small firms, Strategic Management Journal 26(13): 1249-1259.

http://dx.doi.org/10.1002/smj.503

Feltham, T. S.; Feltham, G.; Barnet, J. J. 2005. The dependence of family business on a single decision-maker, Journal of Small Business Management 43(1): 1-15.

http://dx.doi.org/10.1111/j.1540-627X.2004.00122.x

Fiol, C. M.; Lyles, M. 1985. Organizational learning, The Academy of Management Review 10(4): 803-813.

Gavetti, G.; Levinthal, D. 2000. Looking forward and looking backward: cognitive and experiential search, Administrative Science Quarterly 45: 113-137. http://dx.doi.org/10.2307/2666981

Grant, R. M. 1996. Toward a knowledge-based theory of the firm, Strategic Management Journal 17(Special issue): 9-122.

Gray, C. 2006. Absorptive capacity, knowledge management and innovation in entrepreneurial small firms, International Journal of Entrepreneurial Behaviour \& Research 12(6): 345-360. http://dx.doi.org/10.1108/13552550610710144 
Hair, J. F.; Anderson, R. E.; Tatham, R. L.; Black, W. 1998. Multivariate data analysis. New Jersey: Prentice Hall.

Halawi, L. A.; McCarthy, R. V.; Aronson, J. E. 2006. Knowledge management and the competitive strategy of the firm, The Learning Organization 13(4): 384-397.

http://dx.doi.org/10.1108/09696470610667751

Hansen, M. T.; Nohria, N.; Tierney, T. 1999. What's your strategy for managing knowledge?, Harvard Business Review 77(2): 106-116.

He, Z.; Wong, P. 2004. Exploration vs. exploitation: an empirical test of the ambidexterity hypothesis, Organization Science 15(4): 481-494. http://dx.doi.org/10.1287/orsc.1040.0078

Ichijo, K. 2002. Knowledge exploitation and knowledge exploration: two strategies for knowledge creating companies, in C. W. Choo, N. Bontis (Eds.). The strategic management of intellectual capital and organizational knowledge. Oxford University Press.

Jordan, J.; Jones, P. 1997. Assessing your company's knowledge management style, Long Range Planning 30(3): 392-398. http://dx.doi.org/10.1016/S0024-6301(97)90254-5

Ketchen, D. J.; Shook, C. L. 1996. The application of cluster analysis in strategic management research: an analysis and critique, Strategic Management Journal 17(6): 441-458.

http://dx.doi.org/10.1002/(SICI)1097-0266(199606)17:6<441::AID-SMJ819>3.0.CO;2-G

Knott, A. M. 2002. Exploration and exploitation as complements, in C. W. Choo, N. Bontis (Eds.). The strategic management of intellectual capital and organizational knowledge. Oxford University Press.

Kogut, B.; Zander, U. 1992. Knowledge of the firm, combinative capabilities, and the replication of technology, Organization Science 3(3): 383-397. http://dx.doi.org/10.1287/orsc.3.3.383

Lee, K. S.; Lim, G. H.; Tan, S. J. 1999. Dealing with resource disadvantage: generic strategies for SMEs, Small Business Economics 12(4): 299-311. http://dx.doi.org/10.1023/A:1008085310245

Levinthal, D. A.; March, J. G. 1993. The myopia of learning, Strategic Management Journal 14: 95-112. http://dx.doi.org/10.1002/smj.4250141009

Maclaran, P.; McGowan, P. 1999. Managing service quality for competitive advantage in small engineering firms, International Journal of Entrepreneurial Behaviour \& Research 5(2): 35-47. http://dx.doi.org/10.1108/13552559910274480

Man, T. W. Y.; Lau, T.; Chan, K. F. 2002. The competitiveness of small and medium enterprises: a conceptualization with focus on entrepreneurial competencies, Journal of Business Venturing 17: 123-142. http://dx.doi.org/10.1016/S0883-9026(00)00058-6

March, J. G. 1991. Exploration and exploitation in organizational learning, Organization Science 2: 71-87. http://dx.doi.org/10.1287/orsc.2.1.71

Maskell, P.; Malmberg, A. 1999. Localized learning and industrial competitiveness, Cambridge Journal of Economics 23: 167-185. http://dx.doi.org/10.1093/cje/23.2.167

Miller, B. K; Bierly, P. E.; Daly, P. S. 2007. The knowledge strategy orientation scale: individual perceptions of firm-level phenomena, Journal of Managerial Issues 19(3): 414-435.

Miller, D.; Friesen, P. H. 1982. Structural change and performance: quantum versus piecemealincremental approaches, Academy of Management Journal 25(4): 867-892.

http://dx.doi.org/10.2307/256104

Mintzberg, H. 1978. Patterns in strategy formation, Management Science 24(9): 934-948. http://dx.doi.org/10.1287/mnsc.24.9.934

Morgan, R. E.; Katsikeas, C. S.; Appuh-Adu, K. 1998. Market orientation and organizational learning capabilities, Journal of Marketing Management 14(4): 353-381.

http://dx.doi.org/10.1362/026725798784959444 
Nath, D.; Sudharshan, D. 1994. Measuring strategy coherence through patterns of strategic choices, Strategic Management Journal 15(1): 43-61. http://dx.doi.org/10.1002/smj.4250150104 Nevis, E.; Di Bella, A.; Gould, J. 1995. Understanding organizations as learning systems, Sloan Management Review 36(2): 73-85.

Nonaka, I. 1994. A dynamic theory of organizational knowledge creation, Organization Science 5(1): 14-37. http://dx.doi.org/10.1287/orsc.5.1.14

Nooteboom, B. 1999. Innovation and interfirm linkages: new implications for policy, Research Policy 28: 793-805. http://dx.doi.org/10.1016/S0048-7333(99)00022-0

O’Dell, C.; Grayson, Jr. C. J.; Essaides, N. 1998. If only we knew what we know: the transfer of internal knowledge and best practice. New York: The Free Press.

O’Donnell, A.; Gilmore, A.; Carson, D.; Cummins, D. 2002. Competitive advantage in small to medium-sized enterprises, Journal of Strategic Marketing 10(3): 205-223.

http://dx.doi.org/10.1080/09652540210151388

Pelham, A. M. 1999. Influence of environment, strategy, and market orientation on performance in small manufacturing firms, Journal of Business Research 45: 33-46.

http://dx.doi.org/10.1016/S0148-2963(98)00026-5

Peng, M. W. 2001. The resource-based view and international business, Journal of Management 27: 803-29. http://dx.doi.org/10.1177/014920630102700611

Petruzzelli, A. M.; Albino, V.; Carbonara, N. 2007. Technology districts: proximity and knowledge access, Journal of Knowledge Management 11(5): 98-114.

http://dx.doi.org/10.1108/13673270710819834

Porter, M. E. 1980. Competitive strategy. New York: The Free Press.

Prahalad, C. K.; Bettis, R. A. 1995. The dominant logic: restrospective and extension, Strategic Management Journal 16(1): 5-14. http://dx.doi.org/10.1002/smj.4250160104

Rivkin, J. 2000. Imitation of complex strategies, Management Science 46(6): 824-844. http://dx.doi.org/10.1287/mnsc.46.6.824.11940

Rothwell, R. 1991. External networking and innovation in small and medium-sized manufacturing firms in Europe, Technovation 11(2): 93-112. http://dx.doi.org/10.1016/0166-4972(91)90040-B

Sadler-Smith, E.; Spicer, D. P.; Chaston, I. 2001. Learning orientations and growth in smaller firms, Long Range Planning 34: 139-158. http://dx.doi.org/10.1016/S0024-6301(01)00020-6

Siggelkow, N. 2001. Change in the presence of fit: the rise, the fall, and the renaissance of Liz Claiborne, Academy Management Journal 44(4): 838-857.

Siggelkow, N. 2002. Evolution toward fit, Administrative Science Quarterly 47(1): 125-159. http://dx.doi.org/10.2307/3069418

Sirén, C. A.; Kohtamäki, M.; Kuckertz, A. 2012. Exploration and exploitation strategies, profit performance, and the mediating role of strategic learning: escaping the exploitation trap, Strategic Entrepreneurship Journal 6: 18-41. http://dx.doi.org/10.1002/sej.1126

Slater, S. F.; Naver, J. C. 1995. Marketing orientation and the learning organization, Journal of Marketing 59: 63-74. http://dx.doi.org/10.2307/1252120

Smith, A. D. 2004. Knowledge management strategies: a multi-case study, Journal of Knowledge Management 8(3): 6-16. http://dx.doi.org/10.1108/13673270410541006

Smith, H. A.; McKeen, J. D. 2003. Developing and aligning a KM strategy, WP Queen's Centre for Knowledge-Based Enterprises.

Spender, J. C. 1996. Making knowledge the basis of a dynamic theory of the firm, Strategic Management Journal 17(Special issue): 45-62. 
Spender, J. C. 1992. Limits to learning from the West, The International Executive 34(September/ October): 389-410. http://dx.doi.org/10.1108/13673270410541006

Stokes, D. 1995. Small business management. London: Letts.

Stoner, C. R. 1987. Distinctive competence and competitive advantage, Journal of Small Business Management 25(2): 33-39.

Terziovski, M. 2010. Innovation practice and its performance implications in small and medium enterprises (SMEs) in the manufacturing sector: a resource-based view, Strategic Management Journal 31(8): 892-902.

Treacy, M.; Wiersema, F. 1993. Customer intimacy and other value disciplines, Harvard Business Review 71(1): 84-93.

Tushman, M. L.; O'Reilly, C. A. 1996. The ambidextrous organization: managing evolutionary and revolutionary change, California Management Review 38(4): 8-30.

http://dx.doi.org/10.2307/41165852

Von Krogh, G.; Nonaka, I.; Aben, M. 2001. Making the most of your company's knowledge: a strategic framework, Long Range Planning 34(4): 421-439.

http://dx.doi.org/10.1016/S0024-6301(01)00059-0

Whitehill, M. 1997. Knowledge-based strategy to deliver sustained competitive advantage, Long Range Planning 30(4): 621-627. http://dx.doi.org/10.1016/S0024-6301(97)00046-0

Wiklund, J.; Shepherd, D. 2003. Knowledge-based resources, entrepreneurial orientation, and the performance of small and medium-sized businesses, Strategic Management Journal 24(13): 1307-1314. http://dx.doi.org/10.1002/smj.360

Zack, M. H. 1999. Developing a knowledge strategy, California Management Review 41(3): 125-145. http://dx.doi.org/10.2307/41166000

Zack, M. H. 2002. Epilogue: developing a knowledge strategy, in C. W. Choo, N. Bontis (Eds.). The strategic management of intellectual capital and organizational knowledge. New York: Oxford University Press, 268-276.

Zack, M. H. 2005. The strategic advantage of knowledge and learning, International Journal of Learning and Intellectual Capital 2(1): 1-20. http://dx.doi.org/10.1504/IJLIC.2005.006803 


\section{ANNEXES}

Annex 1. Distribution across industry classification standards of the sample firms

\begin{tabular}{lc}
\hline \multicolumn{1}{c}{ NACE codes } & Firms \\
\hline$D-$ Manufacturing & $65 \%$ \\
DA - Manufacture of food products and beverages & $11 \%$ \\
DB - Manufacture of textiles & $9 \%$ \\
DD - Manufacture of wood and wood products & $7 \%$ \\
DE - Manufacture of pulp, paper and paper products; publishing and printing & $5 \%$ \\
DG - Manufacture of chemicals and chemical products & $2 \%$ \\
DH - Manufacture of rubber and plastic products & $5 \%$ \\
DI - Manufacture of other non-metallic mineral products & $2 \%$ \\
DJ - Manufacture of basic metals and fabricated metal products & $12 \%$ \\
DK - Manufacture of machinery and equipment & $2 \%$ \\
DL - Manufacture of electrical and optical equipment & $2 \%$ \\
DN - Manufacturing (manufacture of furniture) & $11 \%$ \\
$F-$ Construction & $7 \%$ \\
$G-$ Retail and wholesale trade; motor vehicles, motorbikes and repairing & $9 \%$ \\
of household appliances & \\
$I-$ Transport, storage and communication & $5 \%$ \\
$K-$ Real estate, renting and business activities & $9 \%$ \\
O - Other community, social and personal service activities & $5 \%$ \\
\hline
\end{tabular}

Annex 2. Competitive strategy groups: descriptive statistics

\begin{tabular}{lccc}
\hline \multicolumn{4}{c}{ Groups (No. of firms) } \\
\hline \multicolumn{1}{c}{ Items } & HR-based & PCSQ-based & Total \\
\hline \multicolumn{1}{c}{ Positions of competitive advantage } & $(29)$ & $(27)$ & $(56)$ \\
Number of product lines & & & \\
Variety within a product line & $14 \%$ & $30 \%$ & $21 \%$ \\
Innovation & $3 \%$ & $19 \%$ & $11 \%$ \\
Product quality & $14 \%$ & $4 \%$ & $9 \%$ \\
Pre-sale customer service quality & $34 \%$ & $67 \%$ & $50 \%$ \\
Post-sale customer service quality & $55 \%$ & $52 \%$ & $54 \%$ \\
Price & $62 \%$ & $70 \%$ & $66 \%$ \\
Sources of competitive advantage & $14 \%$ & $33 \%$ & $23 \%$ \\
Fixtures and fittings & & & \\
Owner-manager's experience and skills & $34 \%$ & $15 \%$ & $25 \%$ \\
Staff experience and skills & $100 \%$ & $33 \%$ & $68 \%$ \\
Organizational procedures & $97 \%$ & $0 \%$ & $50 \%$ \\
Organizational culture & $31 \%$ & $26 \%$ & $29 \%$ \\
Relationships with potential customers & $17 \%$ & $22 \%$ & $20 \%$ \\
Relationships with current customers & $48 \%$ & $41 \%$ & $45 \%$ \\
\hline
\end{tabular}


Annex 3. Internal knowledge strategy groups: descriptive statistics

\begin{tabular}{lccc}
\hline \multicolumn{1}{c}{ Groups (No. of firms) } & \\
\hline \multicolumn{1}{c}{ Items } & Exploitation & Exploration & Total \\
\hline & $(22)$ & $(34)$ & $(56)$ \\
\hline Where & & & \\
Organizational members not in charge of R\&D activities & $100 \%$ & $94 \%$ & $96 \%$ \\
Organizational members in charge of R\&D activities & $0 \%$ & $26 \%$ & $16 \%$ \\
Organizational members' job description & $14 \%$ & $59 \%$ & $41 \%$ \\
Organizational members' competence balance sheet & $9 \%$ & $26 \%$ & $20 \%$ \\
Paper database & $50 \%$ & $79 \%$ & $68 \%$ \\
Electronic database & $5 \%$ & $79 \%$ & $50 \%$ \\
How & & & \\
On-the-job individual experimentation (try \& learn) & $100 \%$ & $88 \%$ & $93 \%$ \\
Occasional designed experimentation & $36 \%$ & $85 \%$ & $66 \%$ \\
Planned designed experimentation (budget resources & $0 \%$ & $38 \%$ & $23 \%$ \\
allocation) & & & \\
Internal training & $45 \%$ & $97 \%$ & $77 \%$ \\
Formalization and diffusion of best practices & $36 \%$ & $79 \%$ & $63 \%$ \\
Team working & $9 \%$ & $44 \%$ & $30 \%$ \\
Meeting to share existing know. among organization & $82 \%$ & $68 \%$ & $73 \%$ \\
members & & & \\
Meeting to share new know. among organization & $50 \%$ & $74 \%$ & $64 \%$ \\
members & & & \\
\hline
\end{tabular}

Annex 4. External knowledge strategy groups: descriptive statistics

\begin{tabular}{lccc}
\hline & \multicolumn{3}{c}{ Groups (No. of firms) } \\
\hline & Exploitation & Exploration & Total \\
\hline Items & $(36)$ & $(20)$ & $(56)$ \\
\hline Where & & & \\
Technical and professional institutes & $33 \%$ & $60 \%$ & $43 \%$ \\
Credit and territorial institutes & $17 \%$ & $50 \%$ & $29 \%$ \\
Chambers of commerce & $31 \%$ & $50 \%$ & $38 \%$ \\
Industrial and technology districts and professional & $94 \%$ & $90 \%$ & $93 \%$ \\
assocs. & & & \\
Suppliers & $94 \%$ & $100 \%$ & $96 \%$ \\
Customers & $92 \%$ & $100 \%$ & $95 \%$ \\
Competitors & $94 \%$ & $85 \%$ & $91 \%$ \\
How & & & \\
Generic meetings & $50 \%$ & $90 \%$ & $64 \%$ \\
Site visits & $50 \%$ & $90 \%$ & $64 \%$ \\
Benchmarking & $69 \%$ & $15 \%$ & $50 \%$ \\
Third-party tutoring & $6 \%$ & $65 \%$ & $27 \%$ \\
External training & $47 \%$ & $85 \%$ & $61 \%$ \\
External collaborative learning & $58 \%$ & $95 \%$ & $71 \%$ \\
Cooperative research & $17 \%$ & $70 \%$ & $36 \%$ \\
\hline
\end{tabular}


Carlo BAGNOLI is Associate Professor of Business Policy and Strategy at the Department of Management, Ca' Foscari University of Venice (Italy). He received a Ph.D. in Business Economics at Ca' Foscari University of Venice. He was visiting research fellow at the University of Florida (USA). He is Scientific Director of the Strategic Innovation Business Centre in Portogruaro-Venice (Italy). His research interests include knowledge management, competitive strategy, business model innovation. Carlo's research work has been published in various outlets, including the Journal of Management and Governance, Industrial Management \& Data Systems, Journal of Strategic and International Studies and Journal of Business, Economics and Finance.

Claudio GIACHETTI is Assistant Professor of Strategy at the Department of Management, Ca' Foscari University of Venice. He received a Ph.D. in Business Economics at Ca' Foscari University of Venice. His research interests include competitive dynamics, corporate strategy, product innovation and industrial policy. Claudio's research work has been published in various outlets, including Strategic Management Journal, Strategic Organization, Journal of Operations Management, Technovation, Business History and Journal of Business Economics and Management, among others. 